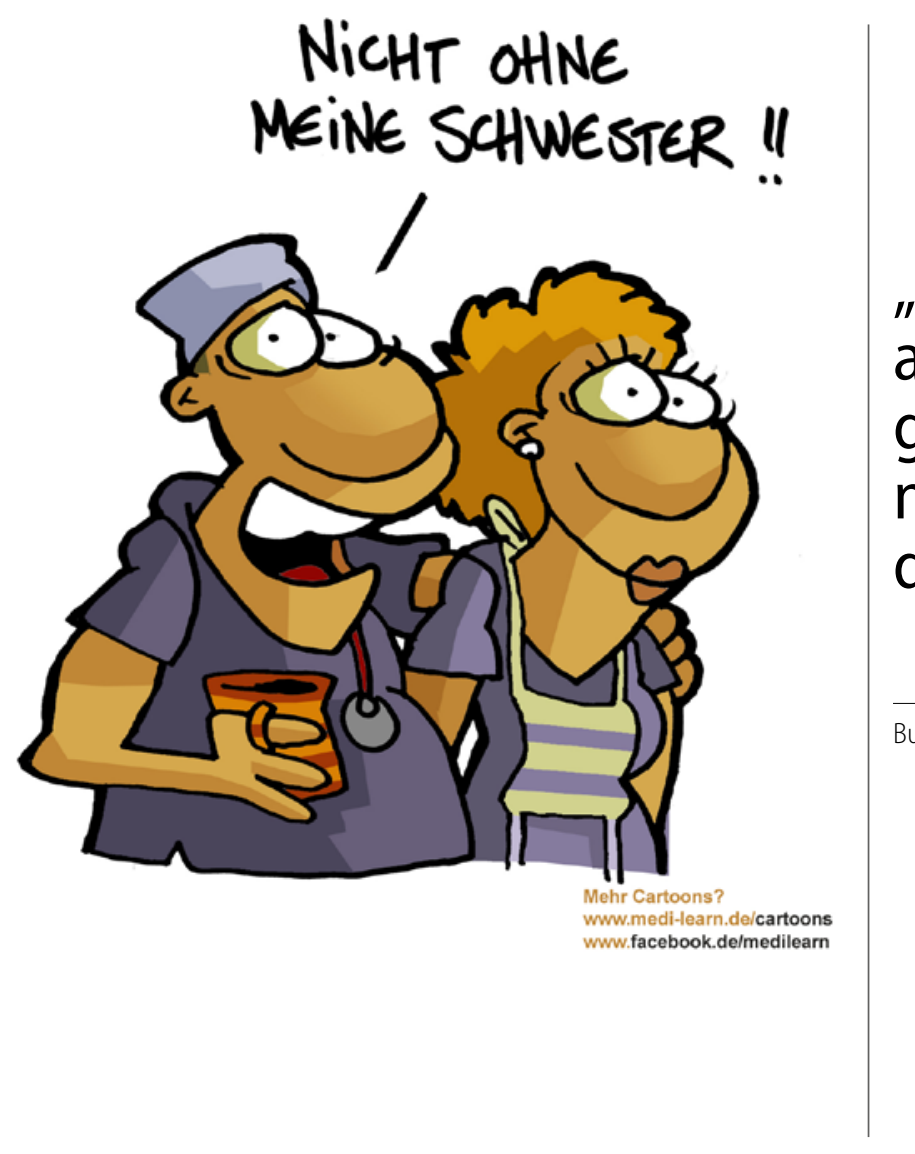

\title{
Angebohrt
}

\section{Ungeteilte Freude}

Die Grenzen des guten Geschmacks sind ja bekanntlich weit dehnbar. Und dass die junge Generation wenig Berührungsängste mit gar nichts hat, ist durchaus auch bekannt und nachvollziehbar. Doch wenn man dazu Zahlen präsentiert bekommt, reißen dann doch eher Abgründe auf. Jüngst stellte ein Telefonkonzern seinen jungen Nutzern eine etwas indiskrete Frage. Diese lautete: Was würden Sie eher teilen: Mobiltelefon oder Zahnbürste? Klar, würde wohl fast jeder hier sagen, ein Freund wird doch mal eben mein Telefon benutzen dürfen. Aber nix da: Nur 4,5 Prozent der 18- bis 24-Jährigen - Männer wie Frauen - würden einem engen Freund die Benutzung des eigenen Handys gestatten. Gut, so ist sie halt, die Generation Eigennutz, deren Glück im Netz und im Always-on liegt. Das Heiligtum gibt man nicht aus der Hand. Aber die Zahnbürste dann doch wohl erst recht nicht, wenn ein schnödes Telefon schon zu intim zum Teilen ist. Aber weit gefehlt: Jeder Zehnte würde laut Umfrage sein eigenes Zahnputzgerät zur Verfügung stellen. Keime? Bakterien? Speichel? Eklig? Nö. Auch Bett und Kleidung würden die Befragten teilen, ohne groß mit der Wimper zu zucken. Während das Handy offenbar Teil des eigenen Selbst ist, ist die Zahnbürste eben nur... eine Zahnbürste. Und ein Mobiltelefon zu teilen ist, als würde man sich mal eben das Gehirn des Freundes ausleihen. Könnte man drüber nachdenken. Besser wäre es vielleicht manchmal.

\section{„Wir müssen sehr darauf achten, dass Dinge nicht gesellschaftsfähig werden, die nicht gesellschaftsfähig sein dürfen."}

Bundeskanzlerin Angela Merkel zu Fremdenhass.

\section{Schneller Putzkick}

Die Olympischen Spiele sind kaum vorbei, da geht es schon weiter mit dem „Höher - Schneller -Weiter" - wenngleich auf ganz anderem Gebiet. Auch bei der zahnmedizinischen Prophylaxe nimmt das sportliche Motto immer häufiger Gestalt an. Meist in Form von Zahnbürsten und anderen Instrumentarien, die dazu dienen sollen, die tägliche Mundhygiene noch effektiver, noch besser und vor allem noch schneller zu machen. Jüngstes Beispiel: Die Turbozahnbürste, die ein italienisches Start-upUnternehmen per Crowdfunding-Kampagne an den Mann, respektive die Frau, bringen will. Wobei das Gerät - angesichts des Werbevideos - vermutlich eher die männlich-technisch-ambitionierten Hirnregionen verzücken dürfte... Aber egal, das neuartige Turboding soll in Sekundenschnelle mit drei Bürsten statt einer die Beißerchen tiptop reinigen. Optisch nicht gerade der Bringer, aber offenbar hocheffizient: Turbobürste (in Form einer etwas überdimensionierten Zahnspange) rein in den Mund, anschalten - zehn Sekunden später ist alles erledigt. Getoppt wird das nur noch von einer US-amerikanischen Erfindung, die das Zähneputzen völlig überflüssig macht: Nanopartikel sollen es richten. Einfach Mund ausspülen, und schon rutschen die Bakterien von den Zähnen ab - per Lotuseffekt (oder so). Tolle Sache. Klare Goldmedaille. Einziges Problem: Probanden für die Nanospülung waren bisher nur Ratten. Aber die sollen dem Menschen ja ähnlicher sein, als man so denkt. sas 